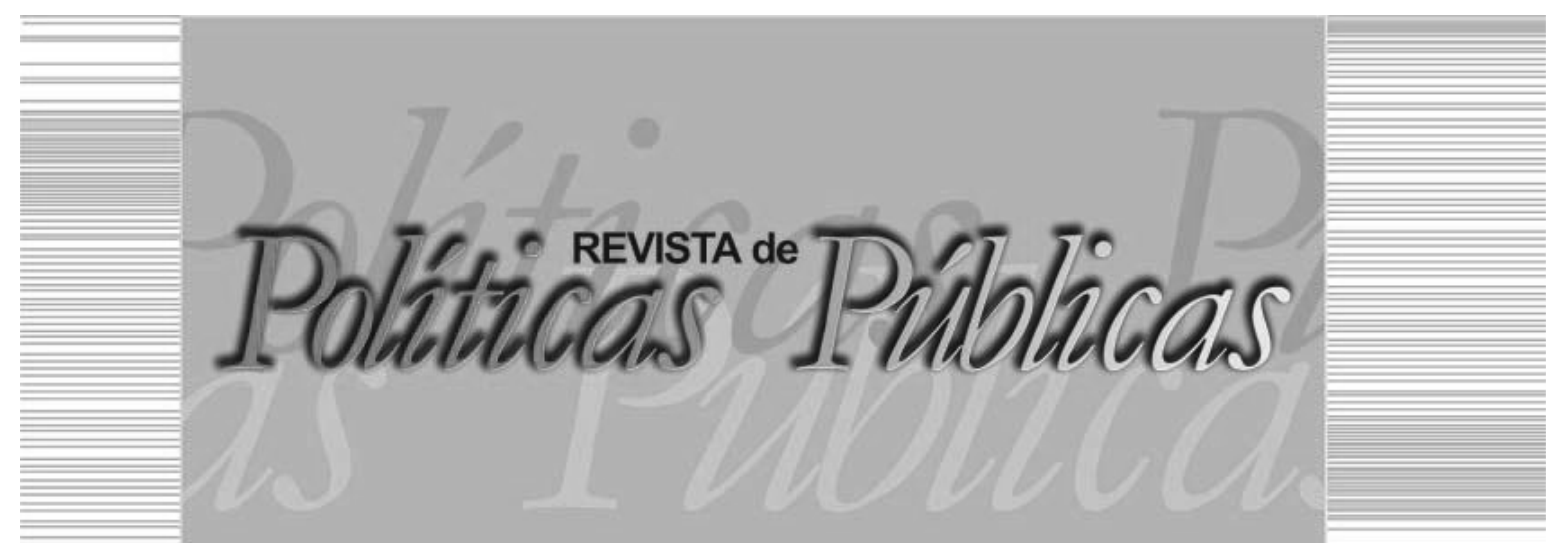

\title{
ANÁLISE DO PROCESSO DE ELABORAÇÃO DE PLANOS DE DESENVOLVIMENTO DE ASSENTAMENTOS RURAIS DO SEMIÁRIDO NORDESTINO
}

\author{
Roberto de Sousa Mirandal \\ Luis Henrique Herminio Cunha ${ }^{2}$
}

\section{Resumo}

A proposta do artigo é analisar o processo de elaboração dos Planos de Desenvolvimento dos Assentamentos José Antônio Eufrosino e Osiel Pereira e o papel das instituições sociais na execução desta política. A metodologia de pesquisa se pauta na revisão de literatura, na realização de visitas, no acompanhamento de assembleias, na consulta ao livro de atas e na realização de entrevistas semiestruturadas com os assentados. Como referencial teórico, adota o neoinstitucionalismo, que ressalta o papel das instituições sociais no empreendimento de ações coletivas e na aquisição de benefícios comuns. O artigo aponta, ainda, que a formulação do Plano de Desenvolvimento do Assentamento se mostrou desafiante porque exigiu uma grande mobilização das famílias para realizar reuniões para deliberar sobre: aplicação do crédito, aquisição de material para construção das casas, atividades produtivas, assistência técnica e infraestrutura básica.

Palavras-chave: Assentamentos rurais, instituições sociais, semiárido, Paraíba.

\footnotetext{
${ }^{1}$ Bacharel em Ciências Sociais, Doutor em Ciências Sociais pela Universidade Federal de Campina Grande (UFCG), Professor do Programa de Pós-Graduação em Ciências Sociais e da Unidade Acadêmica de Ciências e Tecnologia Ambiental da UFCG. E-mail: / Endereço: Universidade Federal de Campina Grande - UFCG: Rua Jario Vieira Feitosa, 1770, Pereiros, Pombal - PB. CEP: 58840000

2 Bacharel em Comunicação Social/Jornalismo, Doutor em Desenvolvimento Sustentável do Trópico Úmido pela Universidade Federal do Pará (UFPA), Professor Associado II e coordenador do Programa de Pós-Graduação em Ciências Sociais da UFCG. E-mail:
} 


\title{
ANALYSIS OF THE PROCESS OF PREPARATION OF DEVELOPMENT PLANS OF RURAL SETTLEMENTS IN NORTHEASTERN SEMIARID
}

\begin{abstract}
The purpose of the paper is to analyze the process of elaboration of Development Plans of Settlements José Antonio Eufrosino and Osiel Pereira and the role of social institutions in the implementation of this policy. The research methodology was based on the literature review of visits, the follow-up meetings, in consultation with the book of minutes and carrying out semi-structured interviews with the settlers. The theoretical framework was neoinstitutionalism, which emphasizes the role of social institutions in the development of collective actions and the acquisition of common benefits. The formulation of the Settlement Development Plan is challenging because it requires a great mobilization of families to hold meetings to discuss: credit application, purchase of equipment for construction of houses, productive activities, technical assistance and basic infrastructure.
\end{abstract}

Key words: Rural settlements, social institutions, semiarid, Paraíba.

\section{INTRODUÇÃO}

A consolidação dos assentamentos rurais é um tema recorrente nos debates sobre as políticas de reforma agrária executadas no Brasil. (BUTH; KRÜGER, 2006; FERRANTE; BARONE; ALMEIDA, 2010; FERRANTE; BARONE, 2011). Dentre os desafios relacionados à conversão dos latifúndios em áreas reformadas, têm sido destacadas, entre outras, as dificuldades dos produtores familiares: terem acesso ao Programa Nacional de Fortalecimento da Agricultura Familiar (PRONAF) (MATTEI, 2015), ao mercado (ARRAES; SOUZA JÚNIOR, 2009) e aos programas institucionais de comercialização. (SANTOS, 2011; SANTANA; BELO; PEDLOWSKI, 2015). A problemática do Plano de Desenvolvimento do Assentamento (PDA), por sua vez, não tem recebido a mesma atenção.

O PDA é uma das primeiras políticas públicas executadas nas áreas reformadas e, de acordo com as Normas de Execução n. ${ }^{\circ} 2$ e n. ${ }^{0} 39$ do Instituto Nacional de Colonização e Reforma Agrária (INCRA, 2001, 2004), exige a participação das famílias na elaboração do documento. Esse processo é extremamente desafiante, pois demanda que as famílias assentadas definam questões que irão orientar a vida social e produtiva futura. A disponibilidade de linhas de cré- 
dito para a produção agropecuária é um dos aspectos que depende da aprovação do PDA.

Enquanto instrumento de políticas públicas, o PDA se constitui a ação estruturante dos projetos de assentamentos rurais porque estabelece os procedimentos para a execução de políticas posteriores, especialmente as de moradia e as de produção. $\mathrm{O}$ anexo 2 da Norma de Execução n. ${ }^{\circ} 2$ do INCRA, que regulamenta a elaboração e supervisão do PDA, destaca que o documento final deve conter informações sobre: (1) aplicação do crédito de apoio à instalação, (2) acesso do beneficiário à capacitação básica e treinamento, (3) execução dos serviços topográficos; (4) aquisição de material para construção das casas, (5) implantação de atividades produtivas (o que pode ser financiado pelo PRONAF), (6) disponibilização de assistência técnica, (7) implementação de infraestrutura básica. (INSTITUTO NACIONAL DE COLONIZAÇÃO E REFORMAAGRÁRIA, 2001).

Portanto, o PDA é o documento que deve conter dados técnicos da área, localização e acesso; as condições ambientais e climáticas; os sistemas produtivos desejados pelas famílias assentadas e mais adequados à região (de acordo com as condições climáticas e de acesso a água, por exemplo); os serviços necessários à produção e à capacitação técnica; informações das famílias assentadas, histórico da ocupação da área, o perfil etário e escolar e os tipos de organização social existentes; e contar com a participação das famílias para que sejam definidos os usos da terra (áreas coletivas e áreas individuais), formalizados no parcelamento, e a existência de agrovilas ou não.

Quando um assentamento rural for classificado nas fases ${ }^{1} 5$, assentamento em estruturação, ou 6, assentamento em consolidação, o PDA poderá ser revisto a partir de um Plano de Recuperação do Assentamento (PRA). Desse modo, O PRA representa um conjunto de ações complementares ao PDA, de reformulação ou de substituição, que possam garantir um desenvolvimento sustentável do assentamento rural, possibilitando crescimento da renda, geração de emprego, aumento da produção e melhores condições de vida. (INSTITUTO NACIONAL DE COLONIZAÇÃO E REFORMA AGRÁRIA, 2001).

Nesse sentido, propõe-se analisar o processo de elaboração do PDA de dois assentamentos do Semiárido nordestino, inseridos 
no Agreste paraibano, mediados pelo Movimento dos Trabalhadores Rurais Sem-Terra (MST), a saber, José Antônio Eufrosino, localizado no município de Campina Grande, e Osiel Pereira, localizado nos municípios de Areia e Remígio, ambos inseridos no Agreste do Estado da Paraíba; enfatizando o papel das instituições sociais dos assentamentos, dos movimentos sociais rurais e do Estado na execução desta política.

A realização deste trabalho teve início com financiamento do Edital das Ciências Humanas e Sociais do Conselho Nacional de Desenvolvimento Científico e Tecnológico (CNPq) e ocorreu a partir da análise do processo de elaboração do PDA dos assentamentos José Antonio Eufrosino e Osiel Pereira. Os assentamentos foram escolhidos porque possuíam três características em comum: (1) localizados no Semiárido paraibano; (2) possuíam mais de cinco anos de criação, quando da realização da pesquisa; (3) eram ligados ao MST. A metodologia se baseou na consulta a documentos, na realização de entrevistas semiestruturadas e em observações in loco.

No assentamento José Antônio Eufrosino, a pesquisa foi realizada entre maio de 2005 e julho de 2006, a partir de: consulta das Atas da Associação; acompanhamento de 4 assembleias que trataram do parcelamento, de assistência técnica e do acesso e uso dos recursos naturais; realização de 13 entrevistas semiestruturadas com assentados, membros da primeira, da atual diretoria da associação e com assentados que estavam no local desde a desapropriação da terra, para obter elementos que permitissem a avaliação da atuação da associação na coordenação da elaboração do PDA; e observações in loco.

No assentamento Osiel Pereira, a pesquisa foi realizada entre junho de 2006 e janeiro de 2007, e as estratégias de ação foram as mesmas adotadas no assentamento José Antônio Eufrosino: consulta das Atas da Cooperativa (o assentamento não possui associação); acompanhamento de 1 assembleia, que tratou da liberação de crédito para recuperação das casas; realização de 7 entrevistas semiestruturadas com os assentados para obter elementos que possibilitassem a avaliação da atuação da cooperativa na coordenação da elaboração do PDA; e observações in loco.

O artigo está organizado em quatro partes: (1) definição de ação coletiva enquanto estratégia de provimento de um benefício coletivo e de instituições sociais como regras e normas que regula- 
mentam as condutas individuais e, consequentemente, contribuem para o empreendimento de ações coletivas; (2) problematização da constituição dos arranjos institucionais do assentamento José Antonio Eufrosino e do processo de elaboração do PDA; (3) problematização da constituição dos arranjos institucionais do assentamento Osiel Pereira e do processo de elaboração do PDA; e (4) considerações a respeito do PDA enquanto uma política estruturante e dificuldades de mobilização das famílias assentadas.

\section{AÇÃO COLETIVA E INSTITUIÇÕES SOCIAIS}

Certa bibliografia já demonstrou que os assentados têm dificuldade em realizarem ações coletivas continuadas e essa descontinuidade coloca vários problemas para as famílias assentadas: (a) a degradação dos recursos naturais (CUNHA; NUNES; MIRANDA, 2006; MIRANDA, 2007; MIRANDA; SILVA, 2014), pois as instituições, especialmente as formais, não possibilitam a regulação do acesso aos recursos comuns logo após a criação do assentamento; (b) conflitos para demarcar as áreas e uso coletivo e os lotes (MIRANDA, 2007). A superação desses problemas é possível quando as instituições conseguem estipular regras e normas que reduzem os custos sociais $^{2} \mathrm{e}$ as incertezas.

Ação coletiva é a ação empreendida pelos membros de um grupo que procuram adquirir um benefício coletivo (OLSON, 1999). No entanto, cada membro do grupo tem a opção de escolher entre se empenhar ou não na ação. Em outras palavras, dilemas de ação coletiva ou dilemas sociais acontecem sempre que indivíduos em situações de interdependência realizam escolhas em que a maximização do interesse individual, normalmente de curto prazo, gera resultados contraditórios para os interesses do grupo como um todo, no longo prazo (ELSTER, 1994; CUNHA, 2004; OSTROM, 1998).

Ao analisar as organizações de tamanhos e formas distintas, Olson (1999) constata que há um propósito que perpassa a maioria delas, especialmente aquelas que se caracterizam por aspectos econômicos: a promoção dos interesses de seus membros. Desse modo, não há sentido algum em formar uma organização quando uma ação individual independente pode promover os interesses dos indivíduos tão bem ou melhor que uma organização. Por outro lado, quando um determinado grupo de indivíduos possui interesses comuns ou coletivos, a ação individual independente não poderá promover esses 
interesses adequadamente. Nesses casos, as organizações são indispensáveis para a aquisição de benefícios coletivos.

As organizações têm a tarefa de proporcionar benefícios comuns ou coletivos aos seus membros. Os benefícios comuns ou coletivos são usualmente chamados de benefícios públicos. (OLSON, 1999). Um benefício coletivo é aquele que se for consumido por uma pessoa $X_{i}$ em um grupo $X_{1}, \ldots, X_{i}, \ldots, X_{n}$, não pode ser negado a nenhum dos demais membros desse grupo. $O$ fornecimento de bens públicos é, para o autor, caracteristicamente organizacional, já que os benefícios não coletivos comuns sempre podem ser alcançados a partir da ação individual.

O processo de aquisição de um bem público, que ocorre a partir da ação coletiva empreendida pelos membros da organização ou grupo, traz consigo uma contradição entre racionalidade individual e racionalidade coletiva. Embora todos os membros de uma organização tenham um interesse comum em alcançar o benefício coletivo, eles não têm nenhum interesse comum em pagar o custo do provimento do benefício coletivo. Para Olson (1999), a resolução dos dilemas de ação coletiva se dá mediante a atuação de um interventor externo que, através de incentivos independentes e seletivos (positivos ou negativos), estimula os indivíduos a agirem de forma coletiva, especialmente, quando o grupo é grande.

A fim de propor novos modelos de racionalidade, Ostrom (1998) parte do pressuposto de que os indivíduos são limitados racionalmente - que não calculam todas as possibilidades de estratégias nas situações enfrentadas e que, em poucas situações da vida, geram informações sobre todas as ações potenciais possíveis, todos os resultados que podem ser obtidos - e que se empreendem sistematicamente ações coletivas para prover bens públicos ou administrar recursos comuns sem uma autoridade externa que ofereça incentivos ou imponha sanções. Reciprocidade e confiança possibilitam a superação dos dilemas de ação coletiva, sem a necessidade de incentivos ou sanções externas ao grupo.

A reciprocidade é uma norma social que pode ser usada na resolução de dilemas sociais que envolvem um esforço para identificar quem é mais envolvido, avaliar os cooperadores condicionais, recusar a cooperar com os que não agem reciprocamente, e punir os que traem a confiança. (OSTROM, 1998). Todas as normas de reciprocidade compartilham ingredientes comuns que permitem aos 
indivíduos reagirem às ações positivas de outros com respostas positivas e às ações negativas de outros com respostas negativas. Reciprocidade é uma norma básica ensinada em todas as sociedades. (OSTROM, 1998).

Quando muitos indivíduos usam a reciprocidade, há um incentivo para adquirir uma reputação, manter promessas e executar ações, que dependem da cooperação de todos, com custos a curto prazo, mas benéficas à coletividade a longo prazo. A comunidade ou o grupo possui a capacidade de construir arranjos institucionais formais ou informais que possibilitem a resolução de dilemas sociais, facilitem o provimento de benefícios coletivos e permitam o manejo dos recursos naturais ou de uso coletivo. (OSTROM, 1998, 2006).

Desse modo, as instituições sociais possibilitam a redução das incertezas (HALL; TAYLOR, 2003; NORTH, 1990; PETERS, 2003; ROMERO, 1999) ao fornecerem regras e normas que regulam os comportamentos individuais e institucionalizarem o contexto em que se darão as relações sociais, políticas e econômicas. A importância das instituições na vida social, aliás, tem sido um tema recorrente nos debates teóricos e práticos relacionados aos processos constitutivos dos assentamentos rurais. (MIRANDA, 2007).

As associações constituem-se a forma predominante de representação dos assentados, "[...] pelo simples fato de que são uma espécie de 'exigência' do Estado: elas são a 'personalidade jurídica' do assentamento e sua presença é quase obrigatória para o repasse de créditos." (LEITE et al., 2004, p. 113). Nos assentamentos em que não existem associações, outras instituições formais, como as cooperativas, exercem a mediação entre assentados e organismos governamentais.

Nas comunidades rurais, bem como nos assentamentos rurais do Semiárido nordestino, existem práticas socioeconômicas e organizacionais não mercantis (práticas de reciprocidade camponesa: mutirões, relacionados a bens comuns, a festas religiosas, a hospitalidade, etc.) paralelamente às relações mercantis. Estas práticas, que se configuram como instituições sociais informais, são ignoradas pelas políticas de desenvolvimento local e pelas propostas de apoio às associações e às cooperativas, o que resulta na ineficiência das políticas públicas direcionadas a estas comunidades. (SABOURIN, 2013, 2014). 


\section{A ELABORAÇ̃̃O DO PLANO DE DESENVOLVIMENTO DO ASSENTAMENTO JOSÉ ANTÔNIO EUFROSINO}

O assentamento José Antônio Eufrosino está localizado no município de Campina Grande, na Microrregião de Campina Grande e na Mesorregião do Agreste, ocupando uma área de 2.990,6401 ha. Foi criado no ano de 2001, mediante a desapropriação das fazendas Monte Alegre, Castelo, Bonfim e Logradouro, ofertadas ao INCRA pelo antigo proprietário. A ocupação das fazendas foi organizada pelas lideranças do MST e da Federação dos Trabalhadores da Agricultura (FETAG) e ocorreu de forma pacífica. (CUNHA; NUNES; MIRANDA, 2006).

A maioria das famílias assentadas estava acampada no assentamento Venâncio Tomé de Araújo e se deslocou para as áreas das fazendas Monte Alegre, Castelo, Bonfim e Logradouro depois de um acordo com o INCRA. As famílias ligadas ao MST foram mobilizadas e recrutadas pelo trabalho de base feito nos sítios vizinhos e nos bairros periféricos de Campina Grande ou vieram de outros acampamentos. As ligadas à FETAG já moravam nas fazendas desapropriadas ou eram filiadas ao Sindicato de Trabalhadores Rurais de Campina Grande.

A pesquisa empreendida constatou que a mobilização de famílias para lutarem pela posse da terra tende a ser mais fácil do que todas as ações coletivas que necessitam ser empreendidas depois da conquista da posse da terra. A ação coletiva realizada para adquirir a posse de terra, incluindo ocupações e período de acampamento, refere-se a uma ação em que o benefício a ser alcançado é conhecido claramente e as famílias mobilizadas dificilmente conseguiriam a posse da terra lutando individualmente. Uma vez alcançado o benefício, há uma desmobilização, porque a lógica organizativa deixa de ser pautada na coletividade e passa a ser orientada pelas experiências de vida que, no Nordeste, tomam como base a unidade familiar.

Criado o assentamento, houve uma exigência por parte dos agentes públicos para que fosse formada uma associação para mediar a relação entre o Estado e os assentados. As instituições do assentamento José Antônio Eufrosino, portanto, foram sendo criadas de acordo com a necessidade de (re)definição de arranjos institucionais que visassem, especialmente, o empreendimento de ações coletivas para executar e implementar políticas governamentais encaminhadas pelos representantes do INCRA. A partir de 2005, o as- 
sentamento passou a contar com dois tipos de instituições principais: a associação e os núcleos de família ${ }^{3}$.

A formação da associação foi marcada por desencontros. Ao mesmo tempo em que o INCRA orientou a formação da associação, para que as famílias recebessem o crédito de fomento, já havia sido iniciada a elaboração do PDA, com o nome de José Antônio Eufrosino, e os assentados não sabiam que a associação deveria ter o mesmo nome do assentamento. Em virtude do acontecido, o nome da associação teve de ser modificado para Associação dos Trabalhadores Rurais do Assentamento José Antônio Eufrosino. (MIRANDA, 2007).

Os núcleos de família começaram a ser formados em 2003, por iniciativa de lideranças estaduais e regionais do MST, segundo as orientações da nova estrutura organizacional do movimento. (MIRANDA; CUNHA, 2013). No assentamento foram criados quatro núcleos de família que correspondiam, geograficamente, a cada uma das antigas fazendas Logradouro, Bonfim, Castelo e Monte Alegre. Cada núcleo era composto por 25 famílias, tendo dois coordenadores em cada núcleo, um homem e uma mulher, que se reuniam uma ou duas vezes ao mês, para discutir os problemas locais; recolher contribuições; quando necessário, escolher os assentados que iriam participar de cursos e encontros; e, para organizar trabalhos coletivos.

A primeira grande tarefa a ser coordenada pela associação foi a elaboração do PDA do assentamento. Esta é uma ação coletiva estruturante que requer grande mobilização das famílias porque define ações posteriores, como organização do espaço e atividades produtivas. O PDA foi elaborado a partir de um convênio firmado entre a Associação Técnico-Científica Ernesto Luiz de Oliveira Júnior (ATECEL) e o INCRA. O desenvolvimento do trabalho contou com a parceria da Engenharia, Geoprocessamento e Recursos Hídricos Ltda. (ENGERH), e a colaboração da Empresa de Assistência Técnica e Extensão Rural do Estado da Paraíba (EMATER-PB). (BRASIL, 2002).

Apesar de constar no PDA que a elaboração ocorreu em sintonia com as famílias, os assentados afirmam, tacitamente, que não participaram do processo e que a associação passava por problemas internos e tinha dificuldades de solucionar os conflitos socioambientais, como a pesca predatória no açude do assentamento. Alguns as- 
sentados ajudaram os técnicos a colher informações sobre o solo e a vegetação, porém a grande maioria não sabia nem quem eram e, muito menos, o que queriam os técnicos da ATECEL. Os que tinham um pouco de conhecimento não sabiam responder qual era o nome da empresa que estava trabalhando na elaboração do PDA.

Insatisfeitos com a maneira pela qual os técnicos da ATECEL estavam realizando as atividades, ao lerem parte do PDA, os assentados, com o apoio de militantes e lideranças do MST, solicitaram ao INCRA a paralisação da elaboração do PDA. A principal argumentação era que a metodologia empregada não era adequada:

[...] pelo o que nós entendemos por PDA, ele é uma coisa que tem que envolver os assentados, porque PDA já ta dizendo, Plano de Desenvolvimento do Assentamento. Se eu estou fazendo um documento que vai ser responsável pelo desenvolvimento do assentamento, não tem como deixar de fora as pessoas, que fazem parte do assentamento. É a vida deles que está em andamento, não tem como você fazer um PDA aonde só os técnicos trabalham [...], então essa parte não foi feita por parte da ATECEL, foi feita simplesmente a parte "escritorial", que é feita em escritório, fizeram alguns levantamentos, alguns dados, algumas coisas simples, mas não dá forma que deveria ser, e [...] a gente depois, tomando conhecimento deste documento, vimos que algumas coisas estavam equivocadas [...] inclusive o que seria as nossas futuras criações (Informação verbal) 4 .

A fala acima ilustra como a associação teve dificuldade em coordenar uma ação coletiva estruturante de grande importância para as famílias assentadas e para superar dilemas da ação coletiva. Para serem mobilizadas para a elaboração do PDA, as famílias precisariam saber para que serviria o documento e qual a sua importância. A falta de informações contribuiu para que as famílias não cooperassem e, consequentemente, a elaboração do PDA foi comprometida. Como a associação poderia ter ajudado nesse processo? Atuando junto aos técnicos da ATECEL para que fornecessem as informações sobre o PDA e junto às famílias para que, tendo conhecimento sobre o tema, participassem da elaboração.

A primeira versão do PDA procurou regulamentar: (1) a criação de quatro agrovilas, com capacidade para 50 famílias cada; (2) a organização coletiva da piscicultura, da apicultura, da avicultura (criação de galinha caipira para a produção de ovos e de frango para o corte) da caprinocultura, da bovinocultura; (3) o plantio de capim 
para o fornecimento de alimento aos animais; (4) implantação de uma agroindústria de abate de frango e bovinos. Cada uma dessas opções requeria uma comissão específica que regulamentasse o processo produtivo e fizesse o controle de qualidade.

Entre o final de 2003 e o início de 2004, uma equipe da Cooperativa de Prestação de Serviços Técnicos dos Assentamentos da Reforma Agrária (COOPTECARA-PB) - empresa de assistência técnica, vinculada ao MST, que prestava serviços ao INCRA - retomou o processo de elaboração do PDA para realizar mudanças no que já havia sido feito e concluí-lo. As mudanças, relacionadas à criação de animais e culturas a serem plantadas futuramente, contaram com a participação dos assentados, o apoio da associação, dos núcleos de família e da militância do MST.

A fim de agilizar o trabalho, foram organizadas duas frentes de trabalho para ajudar os técnicos da COOPTECARA na locomoção dentro do assentamento: uma composta por assentados das áreas de Logradouro e Bonfim, que se responsabilizavam pelos trabalhos nestas áreas; e uma composta por assentados das áreas de Castelo e Monte Alegre, responsáveis pelas atividades da área. No período, a maioria das famílias foi entrevistada pelos técnicos e assembleias foram realizadas para explicar, aos assentados, o que era PDA e sua importância para o desenvolvimento de futuras atividades agropecuárias.

Apesar do esforço dos técnicos da COOPTECARA e das famílias, o PDA do assentamento não pôde ser concluído, visto que havia uma dificuldade de mobilização das famílias para esse fim, havia uma preocupação maior com o parcelamento, definição das áreas de uso coletivo e dos lotes particulares. Somente as informações referentes ao clima, tipos de solo e recursos hídricos, que já haviam sido colhidas e sistematizadas, estavam completas. As observações e análise das atas mostraram que a organização do processo produtivo não foi realizada ou por não representar o que as famílias realmente queriam plantar e criar ou por não serem viáveis, devido às condições impostas pelas características naturais do assentamento.

A associação e os núcleos de família não foram capazes de mobilizar as famílias para discutirem quais seriam as melhores formas de organização espacial e produtiva. Não quero com isso retirar do processo as dificuldades externas, relacionadas ao tipo de contrato firmado entre a ATECEL e o INCRA, mas ressaltar duas 
questões: (1) que os assentados, através de suas instituições sociais, poderiam ser mais atuantes na fiscalização das políticas executadas pelo INCRA; e (2) que a elaboração do PDA deve ser precedida pela realização do parcelamento, porque a incerteza quanto à localização e tamanho dos lotes compromete toda e qualquer ação coletiva que se pretenda empreender no assentamento.

\section{A ELABORAÇÃO DO PLANO DE DESENVOLVIMENTO DO ASSENTAMENTO OSIEL PEREIRA}

O assentamento Osiel Pereira localiza-se nos municípios de Areia (aproximadamente 100 ha) e Remígio, Estado da Paraíba, nas Microrregiões do Brejo e do Curimataú Ocidental e na Mesorregião do Agreste, ocupando uma área de 2.960,1759 ha. O Decreto 2.250/97 deu início à desapropriação da Fazenda Queimadas, formalizada no dia 07 de dezembro de 1998. Já a emissão de posse e a criação do Projeto de Assentamento datam dos dias 19 de novembro de 1999 e 23 de novembro de 1999, respectivamente. (BRASIL, 2000).

A ocupação da área do assentamento foi organizada por lideranças do MST e apoiada pela diretoria do Sindicato dos Trabalhadores Rurais de Remígio. O INCRA já havia considerado que a Fazenda Queimadas era improdutiva. Mas, a direção do Sindicato não sabia como mobilizar as famílias para ocupar a área. Então, lideranças do MST realizaram um trabalhado de formação com famílias de municípios vizinhos, mobilizaram outras que tinham sido retiradas, por ordem judicial, de fazendas da região, para ocuparem as terras.

Com a criação do assentamento, em 1999, as famílias formaram uma associação que representava 150 famílias. O processo de criação da associação, assim como em muitos assentamentos do país, contou com o apoio de representantes do Sindicato, do INCRA e do MST. As primeiras ações coletivas apoiadas ou coordenadas pela associação foram a elaboração do PDA e a ordenação social e espacial da área.

Devido à dificuldade de superar os conflitos que envolviam as famílias assentadas, foi criada no início de 2002, com apoio e orientação de militantes do MST e representantes do INCRA, a Cooperativa Agropecuária do Assentamento Osiel Pereira Ltda. (COOPAP). A COOPAP passou a representar as famílias ligadas ao MST, inclusive nas audiências para a separação do assentamento, em virtude das tensas disputas entre os assentados. 
Como os conflitos se agravavam a cada dia, o INCRA tomou a inédita decisão, no Estado da Paraíba, de apoiar a divisão do assentamento formalizada no dia 27 de julho de 2002, e a consequente criação de um novo assentamento (Queimadas). As famílias ligadas ao MST ficaram no assentamento Osiel Pereira, que passou a ter 986,7253 ha e 50 famílias assentadas. A sua localização foi significativamente alterada; dos 100 ha localizados no município de Areia, restaram apenas 30 ha e 956,7253 ha no município de Remígio.

Desde então a organização do assentamento passou a ser articulada pela cooperativa e pelos núcleos da família: Cajá, com 15 famílias; Pia com 15 famílias e Lagoa de Jogo, com 20 famílias. Existe também um grupo de mulheres que se reúne para fazer louças de barro e organizar a produção de plantas medicinais que formaram a Associação da Pia ${ }^{5}$, que conta também com a participação de ex-moradoras da fazenda Queimadas e possui sede própria fora do assentamento. (MIRANDA, 2007).

A presença de todos esses arranjos institucionais no assentamento se deve, em parte, à história de vida dos assentados. As famílias do núcleo Pia moravam na área e, portanto, se conhecem há muito tempo, possuem laços de amizade, parentesco e compadrio. As famílias do núcleo Cajá, apesar de serem de regiões diferentes, estão juntas desde a época da primeira ocupação da fazenda. Por sua vez, as famílias do núcleo Lagoa de Jogo chegaram por último e são oriundas de diferentes acampamentos organizados pela direção estadual do MST.

A elaboração do PDA do assentamento Osiel Pereira ${ }^{6}$, assim como no assentamento José Antônio Eufrosino, foi realizada pela ATECEL. O PDA informava que seriam construídas três agrovilas no assentamento, cada uma com 50 famílias. Em relação ao processo produtivo, destacam-se a pecuária, a piscicultura, a apicultura, a avicultura, a suinocultura, a caprinocultura, a ovinocultura, a bovinocultura; a implantação de uma unidade piloto de abate de caprinos e ovinos; e atividades artesanais com o couro de caprinos que envolvam as mulheres e jovens do assentamento.

Ao propor atividades artesanais com couro, por exemplo, os técnicos da ATECEL desconsideraram que as mulheres possuem grande experiência em fabricar louças de barro. Além disso, os assentados ressaltaram que o processo de elaboração do PDA foi muito complicado, acirrou os conflitos entre as famílias ligadas ao Sindi- 
cato e as ligadas ao MST, consideradas forasteiras, e deu início à divisão do assentamento. Como o Sindicato tinha o maior número de famílias, apenas uma assentada ligada ao MST acompanhou a elaboração do PDA.

Segundo depoimentos, foi nessa ocasião que o Sindicato, que teve mais acesso à equipe da ATECEL, começou a desarticular as ações empreendidas por militantes do MST no assentamento:

[...] eles [Sindicato] iam para a base, faziam a desarticulação do movimento. No começo o povo teve acesso ao PDA, viram o que seria plantado no assentamento. Foi feito um monte de levantamento. Depois o Sindicato conseguiu que a coordenadora se afastasse do grupo que estava ligado ao MST. Então, assim, eles não conseguiam mais se reunir com o povo, o povo perdeu a confiança neles. Basicamente eles fizeram o PDA do jeito que eles queriam, pediram apoio ao pessoal do Sindicato, eles disseram que a gente ia plantar isso aquilo (Informação verbal) ${ }^{7}$.

A partir do momento em que o Sindicato tomou a frente dos debates, os técnicos da ATECEL não se dirigiam mais aos assentados e sim à diretoria do Sindicato, que tinha a preocupação de expulsar as famílias ligadas ao MST e deixar o assentamento só para as famílias de Remígio. Ao final da elaboração do PDA, parte dos assentados não concordou com o conteúdo do documento. A organização produtiva não condizia com as experiências das famílias e com as condições climáticas locais. As famílias que já moravam na propriedade foram contra e, juntamente com as ligadas ao MST, não assinaram o PDA.

De maneira geral, a elaboração do PDA foi marcada por desencontros e insatisfação dos assentados. A equipe da ATECEL entrou em contato com alguns assentados para formar uma equipe de trabalho e insistiu em não discutir e debater com todos os assentados quais seriam as culturas e animais mais adequados para as condições do assentamento, levando em consideração as questões climáticas, a experiência agropecuária das famílias e a disponibilidade de assistência técnica.

A estratégia dos técnicos da ATECEL foi concluir, o mais rápido possível, o PDA. Então, para agilizar os trabalhos, apresentou aos assentados algumas opções de atividades agropecuárias e argumentou que elas eram as mais adequadas para a região semiárida. Como o PDA é sempre elaborado no primeiro ano após a criação do 
assentamento, os assentados que auxiliaram a equipe técnica estavam mais preocupados em saber se iriam continuar no assentamento e quando seriam construídas as casas, do que com a elaboração do PDA, o que significa dizer que o PDA deveria ser elaborado após o efetivo estabelecimento das famílias nos seus lotes, quando for o caso, e nas suas casas.

$\mathrm{Na}$ elaboração do PDA, a associação não conseguiu obter da ATECEL as informações necessárias sobre o PDA para discutir com as famílias e muito menos mobilizá-las para que todas as questões referentes ao processo produtivo e à organização espacial do assentamento fossem debatidas e deliberadas coletivamente. Disso, conclui-se que as ações coordenadas pela associação não corresponderam às necessidades dos associados porque: a instituição não foi capaz de superar os dilemas da ação coletiva, mobilizar as famílias para cooperarem; e reduzir as incertezas e os custos sociais associados à realização de reuniões e assembleias.

A primeira atividade agropecuária prevista no PDA a ter linha de crédito disponibilizada foi a criação de galinhas. Em 2004, as famílias receberam o crédito e adquiriram as galinhas, porém, a criação foi um fracasso, quase todas as galinhas morreram. Para amenizar o prejuízo, as famílias venderam as galinhas que restaram e compraram bodes. Em 2005, a direção estadual do MST, através da COOPTECARA, firmou um convênio com o INCRA para a realização do PRA. A elaboração do PRA mobilizou as famílias que, nos núcleos de família, apresentaram suas ideias e as atividades agropecuárias que acreditavam serem mais viáveis.

Os núcleos de família e a cooperativa desempenharam um importante papel na elaboração do PRA, reduziram os custos relacionados à mobilização das famílias e possibilitaram a superação dos dilemas sociais que entravavam as ações referentes à definição do PRA. Ao final de 2005, o PRA foi aprovado e assinado por todos os assentados porque o processo correspondeu às expectativas e as famílias já estavam estabelecidas e preocupadas em obter condições concretas de geração de renda.

\section{CONCLUSÃO}

O PDA é a primeira ação estruturante da vida social e produtiva dos assentados e uma das mais importantes. No entanto, o processo de elaboração do PDA ocorre no período de conflitos e incertezas 
associados à permanência no assentamento e à apropriação dos recursos naturais porque as famílias não sabem sequer o local em que poderão criar animais e cultivar a terra, o que dificulta a mobilização e reunião das famílias para discutirem e tomarem decisões importantes. (CUNHA; NUNES; MIRANDA, 2006; MIRANDA, 2007).

Além das dificuldades internas, a elaboração do PDA é realizada de maneira padronizada. O PDA dos assentamentos José Antônio Eufrosino e Osiel Pereira não representam os anseios e necessidades das famílias, ao contrário, são o resultado de decisões tomadas por poucos assentados que, muitas vezes, estão preocupados com outras questões e aceitam as argumentações dos técnicos responsáveis pelo trabalho que, por sua vez, procuram terminar o trabalho o mais rápido possível.

O descaso na elaboração do PDA é tão significativo, que os documentos dos assentamentos em questão apresentam orientações praticamente idênticas. As formas de organização espacial recomendadas são as agrovilas, a produção agropecuária orientada a receber financiamento é idêntica, e a maneira como o trabalho foi realizado também. A incompatibilidade dos dados do PDA com os interesses das famílias assentadas resulta no fracasso de uma ação que deveria estruturar ações a serem desempenhadas futuramente.

Não quero com isso isentar as famílias assentadas do processo de mediação existente com o Estado, mas ressaltar que o caráter puramente formal de associações e de cooperativas ou a ausência de regras e normas que regulem os comportamentos individuais e coletivos, nos primeiros anos de existência do assentamento, compromete o empreendimento de toda e qualquer ação que se proponha ser estruturante. A questão que se coloca é se a maneira e o momento em que o PDA é elaborado são os mais adequados ou se não seria o caso de primeiro estabelecer as famílias para depois orientar ações futuras. A definição dos regimes de propriedade, as áreas de uso coletivo e as áreas de uso individual, não seria prioritária?

Tendo em vista todas as questões apresentadas, conclui-se que a análise das políticas públicas de reforma agrária destinadas aos assentamentos rurais é imprecisa quando não se avalia o desenho das políticas, o modo e o momento em que são implementadas e, especialmente, o papel desempenhado pelas instituições sociais, que representam as famílias assentadas nos processos de tomada de decisão. Além disso, associações e cooperativas de assentamentos 
ANÁLISE DO PROCESSO DE ELABORAÇÃO DE PLANOS DE DESENVOLVIMENTO DE ASSENTAMENTOS RURAIS DO SEMIARIDO NORDESTINO

rurais influenciam, positivamente ou negativamente, na execução de políticas públicas.

\section{REFERÊNCIAS}

ARRAES, R.; SOUSA JÚNIOR, J. L. Eficácia da política de crédito governamental sobre a renda dos assentados da reforma agrária: um estudo de caso. Revista Organizações Rurais \& Agroindustriais, Lavras, v.11, n.3, p. 466-481, set./dez. 2009.

BRASIL. Ministério do Desenvolvimento Agrário. Plano de Desenvolvimento do Assentamento Osiel Pereira. João Pessoa, 2000. Plano de Desenvolvimento do Assentamento José Antônio Eufrosino. João Pessoa, 2002.

BUTH, F.; KRÜGER, W. C. A reconstrução do território a partir de assentamentos rurais: o caso do assentamento Ramada - RS. Revista Campo e Território, Uberlândia, v. 1, n. 2, p. 152-172, ago. 2006.

CUNHA, L. H. Da "tragédia dos comuns" à ecologia política: perspectivas analíticas para o manejo comunitário dos recursos naturais. Revista Raízes, Campina Grande, v. 23, n. 1/2, p. 10-26, jan./ dez. 2004.

; NUNES, A. M. B.; MIRANDA, R. S. Colapso e reconstrução dos regimes de propriedade e o manejo dos recursos naturais em áreas de assentamento. In: ENCONTRO DA REDE RURAL, 1., 2006, Niterói. Anais... Niterói: UFF, 2006. CD-ROM.

ELSTER, J. Peças e engrenagens das ciências sociais. Rio de Janeiro: Relume-Dumará, 1994.

FERRANTE, V. L. S. B.; BARONE, L. A. "Parcerias" com a cana-deaçúcar: tensões e contradições no desenvolvimento das experiências de assentamentos rurais em São Paulo. Revista Sociologias, Porto Alegre, ano 13, n. 26, p. 262-305, jan./abr. 2011.

FERRANTE, V. L. S. B.; BARONE, L. A.; ALMEIDA, L. M. M. C. Controvérsias do desenvolvimento dos assentamentos rurais em São Paulo: produção para os biocombustíveis e as alternativas de programas municipais. Revista Interações, Campo Grande, v. 11, n. 1 p. 9-21, jan./jun. 2010. 
HALL, P. A.; TAYLOR, R. C. R. As três versões do neoinstitucionalismo. Revista Lua Nova, São Paulo, n. 58, p. 194-223, 2003.

INSTITUTO NACIONAL DE COLONIZAÇÃO E REFORMA AGRÁRIA. Norma de Execução n ${ }^{\circ}$, de 28 de março de 2001. Brasília, DF, 2001. Disponível em: <http://www.incra.gov.br/sites/ default/files/uploads/institucionall/legislacao--/atos-internos/normas/ ne_02_280301.pdf $>$. Acesso em: 13 set. 2016.

. Norma de Execução n ${ }^{\circ}$ 39, de 30 de março de 2004. Brasília, DF, 2004. Disponível em: <http://www.incra.gov.br/sites/ default/files/uploads/institucionall/legislacao--/atos-internos/normas/ ne_39_300304.pdf>. Acesso em: 13 set. 2016.

LEITE, S. et al. Impactos dos assentamentos: um estudo sobre o meio rural brasileiro. São Paulo: EDUNESP, 2004.

MATTEI, L. Políticas públicas de apoio à agricultura familiar: o caso recente do Pronaf no Brasil. Revista Raízes, Campina Grande, v. 35, n. 1, p. 6-20, jan./jun. 2015.

MIRANDA, R. S. Desempenho institucional e a superação dos dilemas sociais em assentamentos do semi-árido paraibano. 2007. 145 f. Dissertação (Mestrado em Sociologia) - Centro de Humanidades, Universidade Federal de Campina Grande, Campina Grande, 2007.

; CUNHA, L. H. H. A estrutura organizacional do MST: lógica política e lógica prática. Caderno CRH, Salvador, v. 26, n. 68, p. 363376, maio/ago. 2013.

; SILVA, R. B. E. . Impactos socioeconômicos das áreas de reserva legal e de preservação permanente sobre a produção agropecuária em assentamentos rurais. In: CONGRESSO LATINO AMERICANO DE SOCIOLOGIA RURAL, 9, 2014, Cidade do México. Anais... Cidade do México: ALASRU, 2014.

NORTH, D. C. Institutions, institutional change and economic performance. Cambridge: Cambridge University Press, 1990.

OLSON, M. Lógica da ação coletiva. São Paulo: EDUSP, 1999.

OSTROM, E. A behavioral approach to the rational choice theory of collective action. American Political Science Review, Washington, D.C., v. 92, n. 1, p. 1-21, mar. 1998.

OSTROM, E. Undertanding institutional diversity. Princeton: Princeton University Press, 2006. 
ANALISE DO PROCESSO DE ELABORAÇÃO DE PLANOS DE DESENVOLVIMENTO DE ASSENTAMENTOS RURAIS DO SEMIÁRIDO NORDESTINO

PETERS, B. G. El nuevo institucionalismo: teoria institucional en ciencia política. Barcelona: Gedisa, 2003.

ROMERO, J. J. Los nuevos institucionalismos: sus diferencias, sus cercanías. In: POWELL, W. W.; DIMAGGIO, P. J. (Comp.). El nuevo institucionalismo en el análisis organizacional. México: Fondo de Cultura Econômica, 1999. p. 7-29.

SABOURIN, E. Acesso aos mercados para a agricultura familiar: uma leitura pela reciprocidade e a economia solidaria. Revista Econômica do Nordeste, Fortaleza, v. 45, n. 5, p. 30-43, out./dez. 2014.

Comercialização dos produtos agrícolas e reciprocidade no Brasil. Revista Estudos Sociedade e Agricultura, Rio de Janeiro, v. 21, p. 5-33, abr. 2013.

SANTANA, C. M.; BELO, D. C.; PEDLOWSKI, M. A. Os principais desafios para a institucionalização do PAA nos assentamentos de reforma agrária no Norte fluminense. Revista Campo e Território, Uberlândia, v. 10, n. 20, p. 62-87, jul. 2015.

SANTOS, R. O. C. O que teve de reforma agrária no governo Lula? Revista Campo e Território, Uberlândia, v. 6, n. 12, p. 63-78, ago., 2011.

\section{Notas:}

1 O INCRA utiliza um sistema de classificação de assentamentos rurais composto por 9 fases: (1) pré-projeto de assentamento, (2) assentamento em criação, (3) assentamento criado, (4) assentamento em instalação, (5) assentamento em estruturação, (6) assentamento em consolidação, (7) assentamento consolidado, (8) assentamento cancelado, (9) assentamento revogado.

2 Os custos sociais são relativos à mobilização das famílias para se reunirem periodicamente a fim de definir e redefinir os arranjos institucionais necessários à organização social, produtiva e de acesso e uso dos recursos naturais.

3 Os núcleos de família possuem entre 15 e 25 famílias e são coordenados por um homem e uma mulher, e fazem parte da estrutura organizacional do MST implementada a partir de 2003 para facilitar a articulação interna do movimento (MIRANDA; CUNHA, 2013).

4 Assentado membro da direção estadual do MST.

5 As principais atividades da associação são organizar e manter a tradição de fabricar louças de barro e realizar festas nas principais datas comemorativas do ano (dia das Mães, dia dos Pais, Páscoa, Natal etc.).

6 O PDA foi elaborado antes da divisão do assentamento, por isso os dados se referem às 150 famílias e não a 50.

7 Assentada do núcleo Pia, ex-membro da diretoria da cooperativa, coordenadora do núcleo, membro do grupo de mulheres, e militante do MST. 
